\title{
CARACTERIZAÇÃO FENOLÓGICA E PRODUTIVA DA VARIEDADE DE UVA SUPERIOR SEEDLESS CULTIVADA NO VALE DO SÃO FRANCISCO ${ }^{1}$
}

\author{
LEILSON COSTA GRANGEIRO², PATRÍCIA COELHO DE SOUZA LEÃO, JOSÉ MONTEIRO SOARES ${ }^{3}$
}

\begin{abstract}
RESUMO - A variedade Superior Seedless, devido não somente às excelentes características morfológicas, mas também ao agradável sabor de seus frutos, tem se destacado nos últimos anos como a principal uva sem sementes cultivada no Vale do São Francisco. Este trabalho teve por objetivo caracterizar o comportamento fenológico e produtivo da variedade de uva Superior Seedless cultivada no Vale do São Francisco. As avaliações foram realizadas em uma área comercial, durante o segundo semestre de 1999 e primeiro semestre de 2000. A variedade Superior Seedless apresentou ciclo médio de 94 dias, sendo que, quando a poda foi realizada no primeiro semestre, ocorreu uma antecipação da colheita em 14 dias. A produtividade foi muito baixa $\left(5,3\right.$ t.ha $\left.^{-1}\right)$, mas as características qualitativas como diâmetro e comprimento de baga, sólidos solúveis totais e acidez total titulável, atendem aos padrões exigidos pelo comercio internacional.
\end{abstract}

Termos de indexação: uva sem sementes, fenologia, produtividade.

\section{PHENOLOGIC AND PRODUCTIVE CHARACTERIZATION OF SUPERIOR SEEDLESS GRAPE CULTIVAR IN THE SÃO FRANCISCO VALLEY}

\begin{abstract}
The Superior seedless grape cultivar presents as one of the most important seedless grape, specially due the excelent bunches characteristics and good flavor. In the last years is the most important seedless grape yield in the São Francisco Valley. This work aims the phenologic and productive characterization of the Superior Seedless grape cultivar in the São Francisco Valley. The evaluations were obtained in the private farm at 1999 and 2000. The cultivar Superior Seedless presented average cycle of 94 days. The pruning in 16/02/1999 promoted the antecipation of 14 days of the harvest. The average yield was very low, showing good bunch characteristics.
\end{abstract}

Index terms: grape seedless, phenologic, yield.

A região do Vale do São Francisco consagrou-se como pólo produtor e exportador de uvas de mesa de alta qualidade, a partir do cultivo da uva "Itália", com elevado padrão tecnológico. Nos últimos anos, os viticultores tem-se preocupado em diversificar a produção vitícola com a introdução de novas variedades não somente para evitar a saturação do mercado com a oferta exclusiva de uva Itália, mas também para adaptarem às novas exigências do mercado interno e principalmente externo pela preferência ao consumo de uvas sem sementes.

Algumas variedades de videira sem sementes foram avaliadas na região, destacando-se a Perlette (Camargo et al., 1997), a Vênus e a Marroo Seedless (Leão, 1999). Entretanto, apesar de todas apresentarem boas características de qualidade (diâmetro de bagas e teor de açúcar) e produtividade satisfatória, as preferências do mercado externo por outras variedades limitaram o seu cultivo.

Há aproximadamente quatro anos, algumas empresas do Vale do São Francisco iniciaram o cultivo comercial de uvas sem sementes, com o plantio de uma variedade americana, patenteada pela empresa Sun World, denominada 'Superior Seedless' ou 'Sugraone', e também conhecida na região como
Festival.

Esta, caracteriza-se pela sua precocidade, com ciclo médio entre 90 e 100 dias, dependendo da época de poda; e excelentes características comerciais, como tamanho de cacho e de baga, baixa acidez e sólidos solúveis totais superior a $15^{\circ}$ Brix; no entanto, a produtividade é baixa e irregular. O presente estudo teve como objetivo avaliar o comportamento fenológico e produtivo da variedade de videira Superior Seedless, cultivada na região do Vale do São Francisco.

As avaliações foram realizadas em uma empresa produtora de uvas do Vale do São Francisco, no segundo semestre de 1999 (ciclo 1999.2) e no primeiro semestre de 2000 (ciclo 2000.1). Foram selecionadas 20 plantas de videira da variedade Superior Seedless no segundo ano de produção, enxertadas sob o porta-enxerto IAC 572. A poda realizada foi do tipo mista, deixando varas longas (média 15 gemas/vara) e esporões (3-4 gemas). Após a poda e torção dos ramos, aplicouse via pulverização o produto comercial Dormex a $3 \%$. Para proporcionar o aumento dos cachos e das bagas, duas pulverizações com ácido giberélico foram realizadas, sendo a primeira antes da abertura das flores e a segunda quando a baga

1 (Trabalho 083/2001). Recebido: 03/04/2001. Aceito para publicação: 11/10/2001.

2 Eng ${ }^{\mathrm{o}}$ Agro M.Sc. Doutorando em Produção Vegetal FCAV/UNESP. leilson@fcav.unesp.br

3 Pesquisador Embrapa Semi - Árido, Caixa Postal 23. Petrolina - PE, CEP 56300 - 000.

Rev. Bras. Frutic., Jaboticabal - SP, v. 24, n. 2, p. 552-554, agosto 2002 
estava na fase "chumbinho" (aproximadamente 45 dias após a poda), nas concentrações de 5 e 10 ppm, respectivamente. As observações fenológicas foram realizadas durante todo o ciclo, a partir da poda até a colheita, utilizando-se a classificação proposta por Eichorn e Lorenz (1977).

Os seguintes estádios fenológicos foram observados: E1 - período da poda a início de brotação; E2 - início de brotação à plena floração; E3 - período da plena floração ao início do amadurecimento de bagas; e E4 - início do amadurecimento das bagas à plena maturação. Por ocasião da colheita, foram avaliados, em cada uma das 20 plantas, o número e o peso médio de cachos e a produtividade. Em seguida, dois cachos por planta foram selecionados e levados para o laboratório de Pós-colheita da Embrapa Semi- Árido, para a realização das seguintes avaliações: comprimento e diâmetro de bagas $(\mathrm{mm})$, sólidos solúveis totais ( ${ }^{\circ}$ Brix), acidez total titulável ( $\mathrm{g}$ de ácido tartárico/ $100 \mathrm{~mL}$ de suco) e relação sólidos solúveis/acidez total titulável.

De acordo com a Tabela 1, observa-se que a variedade Superior Seedless apresentou uma variação no número de dias, para cada fase fenológica entre os dois ciclos, com ciclo médio da poda à colheita de 94 dias. A mesma pode ser considerada precoce, quando comparada a outras variedades como 'Itália' e 'Redglobe', mais plantadas no Vale do São Francisco, que apresentam, em média, ciclo da poda à colheita de 120 dias. Entretanto, quando avaliada no Estado de São Paulo, a variedade Superior Seedless apresentou ciclo de 130 dias (Leão et al., 2000).

A época de poda influenciou na duração do ciclo fenológico, sendo que a poda realizada no primeiro semestre (16/ 02/2000) ocasionou uma antecipação de 14 dias na colheita. Geralmente, o ciclo das videiras no Vale do São Francisco é reduzido no primeiro semestre do ano. Isto, muito provavelmente, é devido às condições climáticas, principalmente temperatura. Neste período, as temperaturas máxima (diurna) e mínima (noturna) são maiores em relação ao segundo semestre, o que proporciona uma antecipação da maturação dos frutos.

Os dados referentes à caracterização produtiva são apresentados na Tabela 2. A variedade Superior Seedless apresentou produtividade média de 5,3 t.ha ${ }^{-1}$, bem inferior àquelas obtidas na região com variedades de uva com sementes. Outro fato interessante observado é a superioridade no rendimento das plantas obtida no segundo semestre de 1999. Esta irregularidade tem caracterizado o comportamento desta variedade na região do Vale do São Francisco. As condições climáticas, principalmente temperatura e luminosidade no momento da diferenciação floral, podem ser os principais responsáveis por este comportamento; no entanto, não se pode deixar de lado o grande efeito que o manejo cultural exerce.

O peso médio de cachos foi de $280 \mathrm{~g}$, inferiores aos 468 g encontrados por Sansavini \& Fanigliulo (1998), quando trabalharam com esta variedade na Itália. O comprimento e diâmetro médio de bagas foram, respectivamente, 22,33 e 19,10 mm. A 'Superior Seedless' apresenta, como grande vantagem diferencial, o excelente diâmetro de bagas, bem superiores a outras variedades de uvas sem sementes avaliadas na região, por Leão (1999), (Thompson Seedless 16,01 mm; Marroo Seedless 18,26 mm e Vênus 17,83) e Camargo et al. (1997) (Perlette 17,64 $\mathrm{mm}$; Centennial Seedless 18,17 mm e Catalunha $16,85 \mathrm{~mm}$ ). No Vale do São Francisco, o diâmetro de bagas e o peso médio de cachos mínimos para uva sem sementes, considerado para exportação, são 19 mm e 250 g, respectivamente (Brazilian Grapes, 1999).

TABELA 1 - Duração em dias, dos diferentes estádios fenológicos da videira, variedade Superior Seedless, Petrolina - PE, 1999 - 2000.

\begin{tabular}{|c|c|c|c|c|c|c|}
\hline \multirow[t]{2}{*}{ Ciclo } & \multirow[t]{2}{*}{ Datade poda } & \multicolumn{4}{|c|}{ Estádios fenológicos* } & \multirow[b]{2}{*}{ Total } \\
\hline & & E 1 & E 2 & E 3 & E 4 & \\
\hline 1999.2 & $16 / 08 / 1999$ & 12 & 20 & 35 & 34 & 101 \\
\hline \multirow[t]{2}{*}{2000.1} & $16 / 02 / 2000$ & 8 & 19 & 36 & 24 & 87 \\
\hline & M édia & 10,0 & 19,5 & 35,5 & $\mathbf{2 9 , 0}$ & 94,0 \\
\hline
\end{tabular}

TABELA 2 - Comportamento produtivo da videira variedade Superior Seedless, Petrolina-PE, 1999 - 2000.

\begin{tabular}{|c|c|c|c|}
\hline Características & Ciclo 1999.2 & Ciclo 2000.1 & M édia \\
\hline Produtividade (t.ha $\left.{ }^{-1}\right)$ & $7,41 \pm 2,58$ & $3,20 \pm 0,83$ & 5,30 \\
\hline Número de cachos por planta & $24,10 \pm 7,67$ & $14,45 \pm 4,72$ & 19,30 \\
\hline Peso médio de cacho ( $g)$ & $310,0 \pm 29,47$ & $250,0 \pm 20,36$ & 280,0 \\
\hline Comprimento de baga $(\mathrm{mm})$ & $22,56 \pm 0,29$ & $22,11 \pm 0,38$ & 22,33 \\
\hline D iâmetro de baga $(\mathrm{mm})$ & $19,20 \pm 0,21$ & $19,0 \pm 0,23$ & 19,10 \\
\hline Sólidos solúve is to tais $\left({ }^{\circ} \mathrm{B}\right.$ rix $)$ & $16,55 \pm 0,84$ & $18,1 \pm 0,07$ & 17,32 \\
\hline $\begin{array}{l}\text { Acidez total titulável (g de ácido tartárico/100 mL } \\
\text { suco) }\end{array}$ & $0,448 \pm 0,02$ & $0,464 \pm 0,02$ & 0,456 \\
\hline Sólidos solúveis/Acidez titulável & $37,12 \pm 3,82$ & $39,31 \pm 1,99$ & 38,21 \\
\hline
\end{tabular}


O teor de sólidos solúveis totais pode ser considerado muito bom, nos dois ciclos, com média superior a $17^{\circ}$ Brix (Tabela 2), ficando acima do recomendado pelas normas internacionais de comercialização, que é de $17^{\circ}$ Brix para uvas de mesa (Barros et al., 1995); sendo adotada no Vale do São Francisco, para as variedades sem sementes, valores mínimos de $15^{\circ}$ Brix.

A 'Superior Seedless' destacou-se com baixa acidez total titulável (Tabela 2), o que diferencia esta variedade de outras produzidas na região, sendo bastante inferior ao encontrado na variedade Itália por Lima (1998), e daquelas sem sementes por Camargo et al. (1997) e Leão (1999). Esta baixa acidez contribuiu para uma relação sólidos solúveis/acidez titulável alta, bem superior ao considerado ideal pela literatura, que é 20 (Bleinroth, 1993).

Pelas características apresentadas, a variedade Superior Seedless, constitui-se em uma boa alternativa para a viabilização da produção de uva sem sementes no Vale do São Francisco, devido às boas características de cachos e bagas, sabor agradável, o que lhe confere excelente aceitação no mercado internacional. No entanto, a baixa e irregular produtividade demonstram dificuldades na adaptação desta variedade às condições climáticas tropicais semi-áridas, necessitando, desta forma, de maiores pesquisas nas técnicas de manejo cultural.

\section{REFERÊNCIAS BIBLIOGRÁFICAS}

BARROS, J.C. da S.M. de; FERRI, C.P.; OKAWA, H. Qualidade da uva fina de mesa comercializada na Ceasa de Campinas, 1993 - 1994. Informações Econômicas, São Paulo, v.25, n.7, p. 53 - 61, 1995.

BLEINROTH, E.W. Determinação do ponto de colheita. In: GORGATTINETO, A.; GAYET, J.P.; BLEINROTH, E.W. et al. Uva para exportação: procedimentos de colheita e pós-colheita. Brasília: EMBRAPA - SPI/FRUPEX, 1993.p.20 -21. ( Publicações
Técnicas, 2).

BRAZILIAN GRAPES Instrutivo: Controle de qualidade - safra II/99. [Petrolina, PE], 1999. Paginação irregular.

CAMARGO, U.A., MASHIMA, C.H., CZERMAINSKI, A.B.C. Avaliação de cultivares de uvas apirênicas no Vale do São Francisco. Bento Gonçalves,RS: EMBRAPA - CNPUV, 1997. (Circular técnica, 26).

EICHORN, K.W., LORENZ, H. Phaenologische Entwicklungstadien der Rebe. Nachrichtenblatt des Deutschen Pflanzenschutzdienstes, Stuttgart, n.29, p.119-120, 1977.

LIMA, M.A.C. de. Desenvolvimento, maturação e armazenamento refrigerado de uva 'Itália' sob influência do cálcio. 1998. 121f. Dissertação (Mestrado em Fitotecnia), Universidade Federal do Ceará, Fortaleza - CE, 1998.

SANSAVINI, S., FANIGLIULO, G. Fertilità delle gemme e influenza della potatura sulla fruttificazione delle uve apirene "Centennial Seedless" e "Sugraone". Revista di Frutticoltura, n.2, p.55 - 60, 1998.

LEÃO, P.C.S. Avaliação do comportamento fenológico e produtivo de seis variedades de uva sem sementes no Vale do Rio São Francisco. 1999. 124f. Dissertação (Mestrado em genética e melhoramento de plantas), Faculdade de Ciências Agrárias e Veterinárias, Universidade Estadual Paulista, Jaboticabal, 1999.

LEÃO, P.C.S., NACHTIGAL, J.C., PEREIRA, F.M., KOBA, V.Y. Comportamento fenológico e produtivo das variedades de uva 'Ribol' e 'Superior Seedless' na região de Jaboticabal, SP. Revista Brasileira de Fruticultura, Jaboticabal, v.22, n.2, p.300 - 302, 2000. 